\title{
The development of homogeneity psycho cognition learning strategy in physical education learning
}

\author{
Albertus Fenanlampir ${ }^{1}$, Marleny Leasa ${ }^{2}$, John Rafafy Batlolona ${ }^{3}$ \\ ${ }^{1}$ Department of Physical Education, Health and Recreation, Pattimura University, Ambon, Indonesia \\ ${ }^{2}$ Department of Primary Teacher Education, Pattimura University, Ambon, Indonesia \\ ${ }^{3}$ Department of Physics Education, Pattimura University, Ambon, Indonesia
}

\begin{tabular}{l} 
Article Info \\
\hline Article history: \\
Received Feb 10, 2021 \\
Revised Jul 12, 2021 \\
Accepted Jul 20, 2021 \\
\hline
\end{tabular}

\section{Keywords:}

Elementary school Homogeneity psycho cognition Sport education

\begin{abstract}
Many future studies have been developed by scientists today in the form of methods, models, strategies, and techniques in improving student learning outcomes that are oriented to psychology and the development of students' intelligence. One of the latest innovations in learning offered in this study is the homogeneity psycho cognition (HPC) strategy. The research objective was to develop the latest learning strategies in physical education, sports, and health learning. This development research uses a 4D model consisting of four stages: define, design, develop, and disseminate to produce products in the form of an HPC learning strategy. This study involved 115 elementary school students in several sample schools in Ambon City as participants. This study found that the HPC learning strategy had been developed following the relevant development directions and procedures. The validation of the HPC strategy by experts indicates that the HPC strategy is feasible to implement with due regard to minor revisions. The results of small and medium-scale trials show that the HPC strategy can improve student learning outcomes.
\end{abstract}

This is an open access article under the CC BY-SA license.

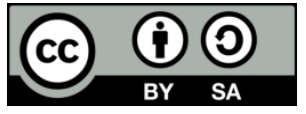

\section{Corresponding Author:}

Albertus Fenanlampir

Department of Physical Education, Health and Recreation, Faculty of Teacher Training and Education Pattimura University

Ambon, Indonesia

Email: fenanlampir29@gmail.com

\section{INTRODUCTION}

Basically, in learning activities, teachers can apply various forms of approach in accordance with the conditions of the class [1], the material to be learned [2], and the level of the educational unit, for example, elementary school [3]. Each of the various approaches used has its advantages and limitations, so the teacher must be skilled and must master the teaching material in addition to the models and learning methods will be used. In general, the approaches that are often used by teachers are teacher-centered learning and studentcentered learning, regardless of what learning strategies, methods or techniques will be used by teachers [4].

Models, approaches, strategies, and learning methods have been developed by experts and are used to improve student learning outcomes [5]. Basically, the teacher only pays attention to the extent to which learning objectives can be achieved, by manipulating the full potential of students without regard to psychiatric, traumatic backgrounds due to unpleasant or bad learning experiences in the eyes of students [6]. Many teacher behaviors are annoying and unfriendly that often accentuate the character of hard, firm and rigid. Even with various verbal threats as well as physical punishment, they severely lessen the courage and intelligence of students to explore themselves optimally [7]. 
Discussions with teachers in Indonesia on various occasions about the mastery of the material and student learning outcomes during learning at school, especially those using cooperative learning models, shows $100 \%$ of the teachers agreed that in the division of groups, students need to pay attention to the level of student intelligence. This is required so the learning process can run optimally, and ultimately, the goals expected by the group can achieve good learning outcomes [8]. From the input, it is known that there is a kind of discrimination in the treatment on "weak" students or those who have low academic ability, or the "slow learners" in the learning process. There is a kind of time discrimination or a kind of coercion in capturing teaching materials and in completing work. This is because learning outcomes are always taken individually, whereas the learning process is carried out in groups. By encouraging group learning, the teacher has ignored individual differences in affection, cognition, and psychomotor domain.

This leads to several thoughts which can be described as: 1) Students who are weak, not smart or slow, must follow the path of thinking of smarter students that more of their nods are only done as a sign of agreement on an opinion instead of an opinion; 2) Smart students often ignore the input from weak students because of their assumed slow thinking ability; 3) Not all students are happily or wholeheartedly taught or instructed by peers (students' attitudes are generally nosy, taunting each other, insulting the poor, weak and slow); 4) Many students need work quietly so working together in groups will be very disturbing to their creative thinking; 5) Students who have traumatic consequences of poor or unpleasant learning experiences from teachers (those who are rude, impatient, angry or punitive) prefer working separately without teacher supervision; 6) In a short-timed tasks, weak students become hasty in completing their work so that the learning results become incomplete, unfinished or incorrect. Based on the facts and conditions, the existence of a cooperative method that involves diversity, togetherness and support from classmates is a positive thing that can help to achieve mastery learning [9]. However, from various backgrounds of learning experiences, mastery and understanding of these students can be very helpful but are also usually very disturbing to the concentration of other students' learning, especially in students with low academic abilities. Thus, it is necessary to develop a learning strategy that is assessed to facilitate students with low academic abilities so that they can enjoy comfortable and coercion-free learning, and achieve optimal learning outcomes.

The results of the development of HPC learning strategies can be used to provide information on student learning outcomes in various subjects at the elementary level and other levels. HPC is a new strategy that has never been developed in any hemisphere. Related to this, in order to enable student learning outcomes to achieve the expected goals, the factor of time duration, intelligence, and learning models are the important indicators to examine its connectivity and its effect on the achievement of learning outcomes. These important indicators are the focus and the strength of this intelligence homogeneity strategy, especially for weak students and slow-learners. The purpose of this study is to analyze the effect of the HPC strategy on primary school students' learning outcomes.

\section{RESEARCH METHOD}

\subsection{Purpose of research}

This research was a development research using the 4D development model [10]. Development research is carried out to develop learning strategies using the Thiagarajaan (4D) model, which consists of four stages: 1) Define: At this stage, curriculum analysis carried out includes task analysis and analysis of student characteristics. Also, the main thing to do is to analyze several learning theories that form the basis for developing HPC learning strategies. In its implementation, the strategy will be conducted through the curriculum used in schools today, the 2013 Curriculum; 2) Design: In this phase, analyses of the teacher's condition, the availability of learning resources such as classroom conditions, teacher and student handbooks are done. The goal is to prepare a prototype of learning strategies. Then at this stage, the learning strategy is developed; 3) Develop: This stage is carried out by reviewing the draft of learning strategy development written by learning experts/validators, doing revisions, and conducting trials to several class teachers and students in three schools. Validators involved in this stage are learning experts/technologists, learning design experts, and learning material experts; 4) Disseminate: In this stage, the learning device products are extensively tested in a number of ways by referring to the mixed method research pattern.

\subsection{Population and research samples}

The population in this study was four grade and fifth elementary school students from four schools in Ambon City. While the sample relates to the stage of research being done. The number of product trial samples for small scales was 48 students and the medium scale trials are 115 students. In the define phase, the initial study was carried out by involving students and teachers. All stages of research development (define, design, and develop) were carried out at all research locations. At the development stage, researchers determined 3-4 elementary pilot projects for the benefit of testing the learning device. It was planned that the 
number of students involved will reach 100-125 students in schools determined by purposive sampling. In this stage, students from four grade and fifth and teaching practitioners and learning practitioners was involved in revising the developed learning products. Before entering the disseminate stage, a lesson study was conducted to equalize perceptions and treatments in learning in research activities at that stage.

\subsection{Research instrument}

Instruments in development research were included: 1) Development product validation sheets; 2) Questionnaire responses of students on individual trials, small groups, and broad-scale; 3) Observation sheet, student response questionnaire, interview guide, and field notes during the study; 4) Instruments of quantitative data measurement which consist of pretest and posttest questions to measure cognitive (theoretical) and psychomotor (practical) learning outcomes. Test questions were developed based on subjects, grade levels, themes/sub-themes temporarily taught.

\subsection{Technic of data analysis}

The research data were analyzed descriptively quantitatively and qualitatively by paying attention to several prerequisite tests according to research interests. Expert validation data and small, medium and large group trials were analyzed with percentages and described qualitatively.

\section{RESULTS AND DISCUSSION}

\subsection{Background on HPC development}

HPC learning strategies are developed based on the results of observations and surveys conducted so far on learning in schools, especially in cooperative learning practices. Cooperative learning in its implementation prioritizes heterogeneity of group members from various aspects, including aspects of cognitive abilities. Based on observations of the practice of cooperative learning, and/or other learning that manages students in study groups, it appears that students with moderate cognitive abilities, especially high cognitive abilities, dominate learning more, while students with low cognitive abilities tend to be ignored. As if such learning does not provide comfortable and enjoyable learning for such students because they are under psychological pressure, fear, doubt, and unconfident in developing their potential. The group seems to be controlled only by certain people who are considered able. Although in fact students with low cognitive abilities are also always encouraged to convey ideas and show active participation in learning, unfortunately most students with such abilities have not been able to show any meaningful changes in learning, whether due to lack of internal motivation and metacognition awareness, a less supportive learning environment, or unmaximized learning management. These kinds of students are reluctant to be actively involved in learning due to several factors, include having a fear of speaking or expressing opinions to others because they recognized themselves as limited or weak. Surely in such situation, anything done is wrong or not necessarily true. Another is the inferiority factor, which is the students realize that they are less significant compared to other students who are always called on by the teacher, are always dependable and respected in learning process. The students also feel bashful because of their limited intellectual condition compared to others. Such emotional conditions also discourage them or make them lack for self-confidence. They may also believe that they cannot catch up with their classmates. This negative perception can affect students' selfconcepts as well as expectations for their educational attainment [11]

\subsection{HPC learning strategies}

\subsubsection{Understanding and objectives of the HPC strategy}

HPC refers to group learning that the HPC learning strategy is a learning strategy that prioritizes cooperation between students in groups to achieve learning objectives, but the grouping is done with homogeneity targets or similarity in students' cognitive abilities. The purpose of forming a cognitively homogeneous group is to provide opportunities for students to be actively involved in the process of thinking and expression in learning activities without feeling burdened by the characteristics of other students who are smarter or more aggressive. It also offers them less regard to the teacher's treatment, characteristics and temperament, as well as his monotonous approach. In this case, most learning activities, like studying the material and discussing to solve problems, are student-centered. Students are divided into small groups and directed to study predetermined subject matter. The HPC learning strategy was formed by prioritizing cooperation in groups as well as cooperative learning.

The HPC strategy is a form of learning strategy that emphasizes the special structure of the homogeneity of the level of student intelligence that has been previously identified by the teacher to influence patterns of student interaction without being burdened with trauma resulting from unpleasant learning experiences. The HPC strategy is developed to increase mastery of interacting, foster self-confidence and 
enhance students' cognitive abilities. This strategy is identical to the type of cooperative learning that involves students in studying the material covered in a lesson and checking their understanding and mastery of the content of the lesson.

\subsubsection{Benefits, strengths, and weaknesses of the HPC strategy}

Related to this, two principles of usefulness have been identified from the implementation of the HPC strategy, namely to students and to teachers. To the students, the strategy is useful to avoid discrimination, foster self-confidence, accept diversity, develop social skills, improve students' performance in academic assignments, and improve learning outcomes. While for the teachers, the strategy can reduce workload, provide more opportunities to guide weak groups and direct intelligent students to the acceleration program so they are not disadvantaged.

In terms of achieving success in learning, each strategy certainly has advantages and disadvantages. However, the advantages and disadvantages can be used as a basis for teachers to determine what strategic steps should be done next. The advantages of the HPC strategy include: 1) Every student becomes ready (no worries, reluctance or inferiority); 2) Students do not feel pressured because the teacher's attitude is not dictating but helping; 3) Students can have a serious discussion; 4) There is no impression of being smart or not clever, skilled or unskilled; 5) There is no hurry in completing group assignments; 6) There is no percentage of group work. As the disadvantages of the HPC strategy are: 1) Not very suitable for a large number of students because it requires a long time; 2) Not all students have the same opportunity to argue or express opinions; 3 ) There is no percentage of the results of group work so that students who like to compete become unenthusiastic. Noting the strengths and weaknesses, the application of HPC learning strategies refers to cooperative science with three steps, namely: formation of groups, discussion of problems, and exchange answers between groups. The steps are then developed into five steps: 1) Teacher's direction; 2) Group formation; 3) Group discussion; 4) Draw Conclusions; and 5) Teacher motivation [12].

Teacher's direction, in this stage the teacher gives general direction about what needs to be done, prepares a learning plan by making a Learning Implementation Plan (RPP), Student Worksheet (LKS) in line with the HPC strategy. The teacher has already obtained the data of each of student's skills. Step 2: Group formation, in a group, formation adapted to the level of intelligence of students. The teacher divides students into groups of 4-6 people. The group formed is a mixture of various social backgrounds, races, ethnicities, religions, and gender. In addition, the formation of groups used pre-test scores as a basis for determining each group. Step 3: Group discussion, in group work the teacher distributes worksheet to each student as material to study. In group work, each student shares their thoughts together to draw answers. They need to make sure that every member knows the answers to the questions in the worksheet or the questions given by the teacher. Questions can vary from general to specific. Step 4: Draw conclusions, students make conclusions about the results of work related to the material presented, then return them to the teacher. Step 5: Teacher motivation, the group submit their work to the teacher. Next, the teacher examines the work and the results obtained by students will not be announced openly to avoid perceptions about the strengths and weaknesses of the answers of each group. Furthermore, the teacher gives reinforcement about the results of group work, motivates and expects students to remain enthusiastic in going through the next learning process. Thus, as the general cooperative learning model, students who are weak, slow or less intelligent, will increase their sense of selfesteem and confidence, among others: more excitement, improved attendance, greater acceptance of individuals, smaller disruptive behavior, reduced conflict between people, deeper understanding, increased kindness, sensitivity and tolerance, and better learning outcomes [13].

\subsection{Elements of the HPC strategy for learning physical education, sports and health in learning strategies in elementary school}

Learning strategy is a learning activity that must be done by learners and students to achieve goals effectively and efficiently. Learning strategies are a set of learning materials and procedures that are used together to produce learning outcomes for students [14]. There are three aspects related to learning strategies, namely learning organizing strategies, learning delivery strategies, and learning management strategies. Strategy can be interpreted as an outline of the direction to be done to achieve predetermined goals. Referring to these elements, the HPC strategy developed in Physical Education, Sports and Health (PJOK) learning in elementary schools, needs to be considered several things.

\subsubsection{Strategies for organizing learning}

This strategy is closely related to the content structure of the field of study. This study examines the development the HPC strategy in learning Physical Education, Sports and Health (PJOK) in elementary school. Physical Education is a learning process through physical activities designed to improve students' physical fitness, develop motoric skills, knowledge, and behavior in healthy and active lifestyles, sports 
attitudes, and emotional intelligence. Physical Education, Sports and Health is a subject that teaches various aspects and health sciences to develop the potential that exists in students' physic and psychology [15]. Physical Education, Sports and Health also allows students to stay healthy and fit, believing that with a healthy body, students can participate actively in all learning process in school to obtain maximum results [16]. Physical Education, Sports and Health learning in elementary schools is included in the thematic content, which is combined with other learning contents such as Pancasila and Citizenship Education, Indonesian Language, Natural Sciences, Social Sciences, Mathematics, Arts, Culture and Crafts (SBDP). Physical Education, Sports and Health learning, although integrated with other subjects in one theme, is still carried out in practices by sports teachers, not by classroom teachers.

Physical Education, Sports and Health learning in elementary school not only develops the physical sphere but also aspects of health, physical fitness, critical thinking skills, emotional stability, social skills, reasoning, and moral action through physical activities and sports activities. Physical Education, Sports and Health is a medium to encourage motoric development, physical abilities, knowledge and reasoning, appreciation of values (attitude-emotional-spiritual-spiritual-and social), and the refraction of healthy lifestyles that lead to stimulating balance in physical growth and emotional development. Physical Education, Sports and Health plays a role in intensifying the organization of education as a process of human development that lasts a lifetime. The learning also provides opportunities for students to create active participation in various physical activities, like playing and exercising in a systematic, directed, and planned manner. Likewise, the learning can equip experiences to foster by creating healthy and active lifestyles throughout life [17].

Physical Education, Sports and Health aims to produce healthy people and develop students' selfpotentials, as well as to develop good moral attitudes, such as honesty and sportsmanship [18]. Through Physical Education, Sports and Health, students are expected to be able to manage themselves to become healthy humans and maintain their physical fitness through activities in the subject [19]. Physical Education, Sports and Health is expected to increase physical growth and develop better psychological. Physical Education, Sports and Health also improves students' basic abilities and movements [20]. Through Physical Education, Sports and Health, the foundation of a strong moral character is laid. Sportsmanship, honesty, discipline, confidence, and responsibility are also developed. Likewise, skills to maintain the self-safety, others and the environment are developed, as well as to achieve perfect physical growth and sportsmanship [21]. The purpose of Physical Education, Sports and Health learning is to provide a variety of mobile experiences to form a solid foundation of motion which in the end is expected to influence active and healthy student lifestyles. The mastery of various basic movement skills by students will encourage the development and improvement of a variety of more complex physical skills, which in turn will help students gain satisfaction and enjoyment in carrying out their physical activities [22].

The HPC strategy is implemented on the theoretical Physical Education, Sports and Health content, thus enabling students to be homogeneously managed to master the theoretical basic concepts the subject is referred to. In thematic learning, Physical Education, Sports and Health concepts include those about games, aquatics, athletics, gymnastics, and health. These concepts require cognitive mastery, so that students' skills are easily honed when practiced. For example, the concept of health includes the cultivation of a healthy lifestyle in everyday life, specifically related to body care to stay healthy, selection of healthy foods and drinks, prevention and treatment of injuries, arrangement of appropriate breaks and active participation in activities on school's healthy environment [23].

In this strategy, there are several learning events to practice. The learning event refers to the opinion that it: attracts attention, conveys the learning objectives to students, stimulates students' memories related to things have been learned, presents teaching materials with the help of relevant learning media, provides tutoring, shows performance, gives feedback on the accuracy of performance, assesses performance, and increases retention and transfer of learning [24].

\subsubsection{Learning delivery strategy}

Learning delivery strategies include ways to convey learning content to students, as well as to receive input from students [25]. The function of the learning delivery strategy is to convey learning content to students, and to provide information or materials needed by students to display performance. In the HPC strategy, the components of the learning delivery strategy include the following.

\section{a. Learning media}

Learning media that are aligned with the HPC strategy include printed media, visual media, and audiovisual media. Printed media in the form of books. Visual media that can be used are strived to meet the visible, interesting, simple, and useful criteria, among which are drawings, charts, diagrams, and posters. Audiovisual media that can be used include TV films, sound films and sound pictures. 


\section{b. Student interactions with the media}

Student interaction with the media through the HPC strategy is expected to stimulate students to engage in learning activities, as well as having a good learning experience. The strategy encourages student interaction with the media, so the learning process can occur. In this strategy, the teacher can develop relevant constructivist learning models. The expected interaction is a two-way interaction between teacher and student, or between student and student, by emphasizing awareness and increasing participation in students who have low cognitive abilities.

\section{c. Learning structure}

The form of learning that is relevant to this strategy is learning in groups. Each group consists of 4-5 people with relatively equal (homogeneous) cognitive qualifications. Data of student's cognitive ability obtained through information on student cognitive learning outcomes in the previous semester/class combined with the study of cognitive test results made by researchers. In each group, students will democratically appoint the group leader whose role is to organize the group. Each person in the group will take turns to lead the group.

\subsubsection{Learning management strategy}

The learning management strategy is a component variable method that deals with how to organize interactions between students and other learning method variables. This strategy is related to making decisions about the organizing strategy and delivery strategy that is used during the learning process [26]. At least, there are three important classifications of management strategy variables, namely scheduling, making notes of student learning progress, and giving motivation. On scheduling, the HPC strategy is planned to be used in learning at least 10 times per semester, adjusted to the availability of theoretical Physical Education, Sports and Health. content. It is associated with the use of media, that every learning process must use relevant learning media, regarding the characteristics of the content of the lesson, the characteristics of students and cognitive development of students.

The progress of student learning is done by observing the development of student learning outcomes through daily tests, midterm assessments, and final semester assessments. Student learning outcomes in the spotlight are cognitive learning outcomes including LOTS and HOTS. Therefore, students are trained to develop cognitive abilities through the design and implementation of learning that emphasizes the empowerment of thinking, for example through questions (LOTS and HOTS levels equally) [27]. The HPC strategy is suggested for the academic empowerment of students who have low cognitive abilities, so that its use can be evaluated through the achievement of cognitive learning outcomes and progress over time.

Motivational management is carried out primarily to increase the internal motivation of students who have low cognitive abilities. Also, external motivation is also sought by giving more attention in ways more specifically to students of low cognitive abilities in priority. In the HPC strategy, student learning outcomes are not given directly to be known by students since it affects learning motivation. Students who receive good grades feel satisfied and encouraged for competence, while grades are thought to reduce intrinsic motivation. Indeed, the lower the student's grades, the internal motivation of elementary students decreases [28].

\subsection{Basis for developing HPC learning strategies \\ 3.4.1. Humanism}

Humanism in learning is based on the principles of humanism developed by several scientists [29]. In this approach, learning is not just about intelligence, but more than that, it is about educating the whole person, where one's interests, goals, and enthusiasm are taken into account, to reach their true potential. This student-centered approach encourages students to take responsibility for their learning and also encourages intrinsic motivation. The main objectives of the humanistic approach are human well-being, including the primacy of human values, development of human potential, and recognition of human dignity [30].

Humanism focuses on human freedom to act and control their destiny. This approach is centered on human values, interests, capacities, needs, values and dignity. It views that a person has unlimited potential for growth and development and is inherently good. Students as individuals can determine whether something is true or not (containing truth or falsehood) through rational and empirical thinking through learning, while learning is seen as the acquisition of new knowledge, behavior, skills, and values. Learning is done through the process of study, practice and experience as an effort to change, shape and control behavior.

The HPC learning strategy makes students not afraid and not forced to learn because they have a sense of continuity and equality with their classmates in learning. This foundation revives students' confidence which once lost or hidden because they are in a surrounding of fellow students who are different, as well as encourages the development of self-confidence, especially in students of low cognitive abilities. 
This school emphasizes students' personal freedom, choices, motivation, self-determination, and personal goals [31]. Implementation of humanism is done by providing a safe learning environment to students, based on the warmth of empathy and acceptance of differences of viewpoint from the teacher. The teacher acts as a facilitator while students control their learning. The learning process can be done individually or in collaboration with other students. This theory allows face-to-face interaction, in small groups, and let students take responsible for the learning process. The positive impact the implementation enables students to gain academic, personal, and life skills through understanding and seeing the world holistically [32].

People are basically good (in a moral sense) and have an innate tendency towards growth and fulfillment of their potential - that is towards self-actualization. So, with the attention, respect, and love of important people, they can grow into people who are fully functional, satisfied, and contributing productively to their society. Without respect and love, their growth towards self-actualization can be blocked and it can cause problems in life. The humanism approach emphasizes that each individual, including students, is unique. Every individual needs to be given space to build trust, openness, and self-disclosure as a basis for creating meaningful relationships. In this approach, each individual is considered to have the responsibility to work towards improvement without differentiating individuals from one another [33].

\subsubsection{Constructivism}

Constructivism encourages students who have difficulties to express their potential because of shame, fear, awkwardness, and the feeling of being forced by conditioning a homogeneous environment, where they have perceptions and feelings of self-satisfaction. Constructivism can trigger students to form or build their own knowledge in a homogeneous group and is believed to be able to accept the results of their work before being shown to other groups whose cognitive abilities are better. Ideas of constructivism emphasize the transmission of knowledge, meaning, and interpretation from teacher to student, and advocates the creation of optimal conditions for students to let them construct the meaning themselves. Constructivism prefers promoting an environment where students can gain knowledge through investigation either personally or in small groups. The teacher in this approach serves to provide guidance. It requires educators who empower their students and increase their motivation and ability to learn and develop through questions. The constructivist learning environment has strived as an environment that allows students to work together in a discovery learning community: a community involved in shared thinking, exploration, and discussion of essential topics [34].

In the view of constructivism, the individual builds his own understanding of the world of knowledge connected with thought and facts, including construction of interpretations of the facts that occur around them [35]. Constructivism is based on the assumption that the individual construction process cannot be influenced from outside. Furthermore, constructivist learning theory often relies on the idea of development which assumes that individuals develop according to the logic of development they construct, therefore education is absolutely necessary [36].

On the other hand, the known constructivist model of human mental activity is the fact that a problem has occurred and appeared in an activity. As a result, individuals need to build various alternatives through their own thoughts in such a way that new forms of activities are obtained and the problems are solved. In contrast to constructivist learning theories that are based on isolated individualism and thought development, pragmatic constructivism is referred to as transactional constructivism [37]. Transactional constructivism views that knowledge is interpreted by an individual, which arises in transactions between individual activities and the environment for action. This means that individual thought and the reality around it are essential in the individual's learning process. Unlike other forms of constructivism, transactional constructivism makes it possible to discuss the relationship between the influence of educators and individual growth, because social interaction between educators and people who grow takes place in a medium that is common to both learnings. The basic idea of the activity model of thinking, based on the creative and constructive actions of the human mind, involves situations where individuals face problems in their actions, then try to solve them by generating hypotheses in the form of concepts. Hypotheses that are formulated into a conceptual language allow the continuation of actions in the desired way [38].

\subsubsection{Progressivism}

Progressivism encourages students to have freedom in ways of thinking that are not supported by the learning environment because they feel they are under pressure from others, both by the teacher and by students who have abilities above them. Students are allowed to develop their potential, creativity, and talent without any pressure from any party. Progressivism emphasizes a means or tool that is prepared to develop students' abilities to survive against all the challenges of their lives that will practically continue to progress [39]. Also, the education process is carried out based on the pragmatic principle. That is, education must be able to provide benefits to students, especially in dealing with problems that exist in the community. 
The idea of progressivism also opposes inhuman education. Humanist education is needed to create more independent learners. Education as a conscious and planned effort made for the creation of a change that is better than before, does not have to be designed and implemented in the form of violence and pressure both physically and psychologically. In this view, students must be given full freedom of space to show a fair attitude to work following their respective ways and abilities. This is done to improve the intelligence and creativity of students. In other words, the principle is freedom of student behavior as an educational subject, while the teacher is a student servant [40].

\subsubsection{Cognitivism}

Regarding the factors that influence the cognitive development of individuals, there is a difference of opinion among adherents of psychology. Radical psychometrics groups argue that about $90 \%$ of intellectual/cognitive development is determined by heredity and environmental influences, while education only contributes around $10 \%$. This group provides evidence that individuals who have superior intellectual heredity will be very easy to develop, even only with fair environmental intervention. Whereas individuals who have low intellectual heredity have difficulty, even with optimal environmental intervention. On the other hand, radical pedagogical groups are very confident that environmental interventions, including education, actually contribute around $80-85 \%$, while heredity only contributes $15-20 \%$ to the development of individual intelligence. The requirement is to provide opportunities or sufficient time for individuals to develop their intelligence optimally. Adopted children who live in a good environment have an IQ increase of up to 5 points, while foster children who live in a bad environment do not experience an increase intelligence level [41].

Heresy of an individual has natural potentials that can cause differences in the development of thinking. The potential of a person to flourish or not depends on environmental factors. This means, whether the child will have the ability to think normally above normal or below normal depends on the environment, both of the school and the family where the child lives and grow. Humans differ from each other in various aspects such as talents, interests, personalities, physical conditions, social conditions, including intelligence [42]. These differences will be seen if observed in the learning process in the classroom: some students are fast in the process of reasoning or understanding a matter, and some others are slow in the thinking process. Likewise, in the form of behavior, some children behave well and some children behave poorly. Individual differences in intellectual development point at differences in the learning speed and ability, in which this will be reflected in their traits or characteristics in abilities, skills, attitudes and learning habits, and the quality of processes and learning outcomes in the cognitive domain.

\subsection{Characteristics of HPC strategies}

The HPC strategy works for traumatic therapy of learning conditions or facts that are considered less humanistic, especially in students who have low cognitive abilities. Therefore, the characteristics of the HPC learning strategy are aimed more at these conditions.

\subsubsection{Grouping students based on aspects of cognitive homogeneity}

Homogeneity of cognitive aspects means that the management of students in groups is based on the homogeneity of cognitive aspects or academic ability. The results of the writer's observation and interviews with students and teachers in various regions in Maluku, indicate that heterogenous students form heterogeneous groups of various aspects including cognitive aspects in cooperative learning. This kind of learning makes smart students become smarter, while the weak ones become weaker because the smart students dominate in active involvement. It also causes traumatic behavior for weak students, because they are often scolded or ridiculed when being slow in doing group tasks. Learning is directed to achieve completeness, without the final grade being given to the students (group scores are kept by teacher, not revealed to students).

Large differences in basic skills and other intellectual disparities among students in heterogeneous classes in school can be overcome by forming homogeneous groupings. Nonetheless, the improvement in learning outcomes and academic achievement in groups of low cognitive students is not comparable to high cognitive students. In this strategy, only cognitive elements are homogeneous, while other aspects remain heterogeneous. Heterogeneity in other aspects, besides cognitive aspects, is a positive resource to encourage cognitive growth through restructuring the learning situation. One pedagogical approach to such restructuring can originate from the view of social constructivism [43]. There are important contribution of social interaction with cognitive development and view cognitive development as a process of continuous interaction between individuals and the environment.

Knowledge is built by individual interactions in society and learning is seen as a result of internalization of social interaction. Interactions that occur in students with homogeneous abilities show the diversity of personal styles, experiences, attitudes and opinions, and consequently force them to overcome the 
controversies, disagreements, and conflicts that rise in such situations to communicate with each other and use each other as resource. Modeling effective learning strategies, cognitive restructuring, and processing that occur as a result of the need to integrate new or conflicting information into one's attention by members of other groups, increases efficiency due to increased information resources and expands the range of abilities needed to find solution to complex tasks, improved exercises and elaboration of learning [44].

\subsubsection{There is an addition in learning time for low cognitive or needy students}

Study time for students' intelligence follows common time standards. The manipulation of time is done by the teacher, without notifying directly to all students. Students with low cognitive abilities show less involvement in learning tasks and tend to have low learning achievement. They often even have some learning difficulties, and limited metacognitive skills. They also show little interest and negative attitude towards learning and sometimes have a poor self-image. Students with low cognitive abilities are encouraged to learn by giving extra time. This provides an opportunity for them to carry out a collaborative inquiry process in which students are continuously involved in the assessment and reflection on the performance and inquiry process. There is positive effect of collaborative inquiry on the performance of those with low cognitive abilities [45]. Besides, there is also certain web-based collaborative inquiry to benefit students who excel and students with underachievement to be enabled to work in progressive inquiry, synthesize ideas and advance the discourse of overall knowledge development [46]. They take responsibility for advancing collective knowledge, organize their investigations when generating new theories and questions, and are responsive to problems and ideas that arise, as well as to expand their horizon.

\subsubsection{Attention is more aimed to students with low cognitive abilities and or students in need}

It will be immediately known by the teacher in learning, that the usually pays more attention on students who have high cognitive abilities. In the HPC strategy, more of teacher's attention is devoted to students who have low academic, so that the learning difficulties encountered can be immediately overcome. The attention given by the teacher is also an effort to provide guidance and motivation to students in such category. Attention can have either positive or negative effects on children's behavior. Relating to teacher's attention, an observational study on preschool students suggests that teachers give less criticism and fewer commands compared to the number of tasks assigned to children [47]. A case study of a six-year-old male student shows that praise and other positive teacher's attention can be done to increase appropriate behavior and reduce bad behavior [48]. All of these studies highlight the importance of teacher's attention in children's school experiences. Given the relationship between children's attention and behavior, it is surprising that some research has investigated the amount and type of teacher's attention received by students. Negative attention includes discipline, orders, insults, and criticism. Positive attention also includes a wide variety of teacher's behaviors, including praise and appreciation [49].

\subsubsection{Judgment is fun}

Knowledge, skills, and concepts learned in Physical Education, Sports and Health contents are not of much use in long term if students do not tend to use them outside the classroom [50]. Therefore, the assessment carried out by Physical Education, Sports and Health teachers is sought to be fun, which means the teacher does not need to submit the results of the assessment directly to students. The results of the assessment are only known by the teacher. What needs to be conveyed to students is that their work is good, everyone has done well, so it should be given a form of appreciation. The teacher rewards all student work in low, medium, and smart groups, because the purpose of learning Physical Education, Sports and Health is to achieve happiness or fun. Nevertheless, the assessment in Physical Education, Sports and Health learning is still carried out for other purposes including: measuring the progress of learning of each student, determining the competency of the special skills students have, determining the need for remedy or acceleration of certain concepts or specific skills, including measuring the effectiveness of the subject's curriculum.

\subsection{Development module validation}

Validation of the results of the development of HPC strategy is carried out by five experts in the field of learning technology, learning in elementary schools, and experts on Physical Education, Sports and Health material. The results of expert validation on the construct of the HPC learning strategy are shown in Table 1. The trial of the development results is carried out by filling in questionnaire of student responses after learning process with the HPC strategy which is done through a small-scale trial in four grade and fifth in one school. Student learning outcomes are shown in Figure 1(a). The final results of a small-scale trial in the form of student responses to learning with HPC strategy indicate that learning with the strategy is considered good (mean score of 77.6). Medium-scale trials of the implementation of HPC strategy are carried out on four grade and fifth in four schools. The trial results are shown in Figure 1. 
Table 1. Results of expert validation on the construct of HPC learning strategies

\begin{tabular}{|c|c|c|c|c|c|c|}
\hline \multirow{2}{*}{ Assessment aspects } & \multicolumn{5}{|c|}{ Score } & \multirow{2}{*}{ Average } \\
\hline & $\mathrm{V} 1$ & $\mathrm{~V} 2$ & V3 & V4 & V5 & \\
\hline Preliminary & & & & & & \\
\hline $\begin{array}{l}\text { The rationality of the background for developing HPC learning strategies is clearly } \\
\text { outlined. }\end{array}$ & 4 & 4 & 4 & 4 & 3 & 3.8 \\
\hline
\end{tabular}
outlined.

Average

HPC Learning Strategies

The understanding of HPC learning strategy is clearly explained

The objectives of HPC learning strategy are clearly outlined

The benefits of HPC learning strategy are clearly outlined

The advantages and disadvantages of HPC learning strategy are clearly outlined

Average

3.8

Elements of the HPC Strategy in Learning Strategies

Strategies for organizing learning are clearly described

The content structure of the field of study/content of the Physical Education, Sports

and Health in the strategy of organizing learning is clearly outlined.

The purpose of the Physical Education, Sports and Health field of study in the strategy

of organizing learning is clearly outlined.

Learning delivery strategies are clearly described.

The components of learning media are clearly described.

The components of student interaction with learning media are clearly described

The components of the structure/form of learning are clearly described.

Learning management strategies are clearly described.

The scheduling component in the learning management strategy is clearly outlined.

The component of making notes on student learning progress in the learning

management strategy is clearly outlined.

The motivational management component in the learning management strategy is

clearly outlined.

Average

4.2

4.0

4.4

4.4

4.25

5.25

Basic Development of HPC Learning Strategies

HPC learning strategy is compatible with the ideas of humanism.

HPC learning strategies in accordance with the ideas of constructivism.

HPC learning strategies in accordance with the ideas of progressivism.

HPC learning strategies in accordance with the ideas of cognitivism.

Average

$\begin{array}{llllll}5 & 3 & 4 & 3 & 2 & 3.8 \\ 4 & 4 & 4 & 3 & 2 & 3.4 \\ 5 & 4 & 3 & 4 & 2 & 3.6\end{array}$

Characteristics of HPC Learning Strategy

The characteristics of grouping students based on aspects of cognitive homogeneity are clearly outlined.

The characteristics of increased learning time are logically described.

The characteristics of grouping students based on aspects of cognitive homogeneity are clearly outlined.

The characteristics of grouping students based on aspects of cognitive homogeneity are described logically.

The characteristics of giving attention to low cognitive students and/or needing are clearly described.

The characteristics of giving attention to low cognitive students and/or needing are described logically.

The pleasant characteristics of the assessment are clearly explained.

Fun assessment characteristics are described logically.

$\begin{array}{llllll}4 & 4 & 3 & 4 & 2 & 3.4 \\ 3 & 4 & 4 & 4 & 2 & 3.4\end{array}$

$\begin{array}{llllll}4 & 3 & 4 & 4 & 2 & 3.4\end{array}$

$\begin{array}{llllll}3 & 4 & 4 & 5 & 3 & 3.8\end{array}$

$\begin{array}{llllll}5 & 4 & 5 & 5 & 2 & 4.2\end{array}$

$\begin{array}{llllll}3 & 3 & 4 & 4 & 2 & 3.2\end{array}$

$\begin{array}{llllll}4 & 4 & 3 & 5 & 2 & 3.6\end{array}$

$\begin{array}{llllll}4 & 4 & 4 & 5 & 3 & 4\end{array}$

3.6 6 
The development of the HPC strategy is one of the spectacular steps to improve learning at the elementary school level. This strategy serves as a guide for following the steps in HPC strategy. It helps teachers to design learning process, make the learning process more effective, and evaluate it properly. It also helps students improve learning independence and involve students in classroom activities. As a result, students can build scientific knowledge through structured thinking skills and gain more meaningful learning through a series of activities in the form of experiments, collaboration in conveying original thoughts, and independent and collective decision-making. Correspondingly, the results of the study stated that elementary school students in Ambon preferred natural activities inside or outside the classroom [51]. This is because the natural condition of Maluku Province comprises small islands, so the students are accustomed to living together with nature, which enables direct learning. Therefore, HPC strategy is developed in this case as a perfect study to accommodate the educational needs in small islands.

The results of the feasibility test by five experts and field trials show that HPC strategy is highly applicable in learning at elementary school level. This is because HPC is a product of constructivism. Moreover, in HPC, the teacher is directed to maintain the psychology of students to keep them from the actions of peers discriminate students with low abilities. HPC also provides the broadest possible space with a relatively long time for students with low ability to think deeply, develop ideas that have not been thought through, convey good ideas in developing scientific concepts. In addition, HPC can also improve learning outcomes from low to high cognitive skills. This is found in small and medium scale trials in which many students have been at very good level. Cognitive skills acquired after using this strategy are the skills to design, analyze, infer, and evaluate the learning process. Previous research findings emphasize the importance of learning strategies that enable teachers to make students meaningful in learning by asking questions both oral and written [52]. This strategy has proven to be very effective in improving students' cognitive skills and learning behavior. Learning from a humane and pleasant environment in participating in group discussions accelerates the mindset.

Learning activities are directed by the teacher in the form of directions. Every student gets an assignment. This activity allows students to be more responsible individually or in groups. In addition, students are also motivated to revolutionize thinking and find the right solution for each problem given by the teacher. Even though students' cognitive skills are different, they are still allowed to learn exploring something new. Questions and answers in learning activities can develop students' creative thinking [53]. The group discussion phase is a form of responsibility to complete assignments given by the teacher in provided material. Students can collaborate and ensure that each group member can produce the right answer. This shows no social differences that a group can help, respect, and accept input from one another in order to solve problems and reach the goals of discussion. Learning strategies or models are not only to increase students' understanding of a particular topic but also to build scientific confidence to work in groups and develop discipline as learners [12].

\section{CONCLUSION}

The research concluded that the Homogeneity Psycho Cognition (HPC) learning strategy has been developed adhered the relevant development directions and procedures. The results of the validation of HPC strategy by experts indicated that HPC strategy was appropriate for application with minor revision. The results of small-scale and medium-scale trials showed that HPC strategy was responded well by students.

Some suggestion should be done as follow up of the conclusion. It is necessary to conduct trials on a broader scale to obtain information about the effectiveness of HPC strategy in various elementary schools in Ambon City and other districts. Experimental research is required to examine the effect of HPC learning strategy on student learning outcomes in Physical Education, Sports and Health and other subjects. It is also necessary to conduct a broader and in-depth research on HPC strategies at various levels of education and subjects in various regions.

\section{ACKNOWLEDGMENTS}

The researcher expresses his gratitude to the Faculty of Teacher Training and Education, Pattimura University for providing research funds through the Social Research, Humanities and Education grant in the 2019 budget year. 


\section{REFERENCES}

[1] S. Dhawan, "Online learning: a panacea in the time of covid-19 crisis," J. Educ. Technol. Syst., vol. 49, no. 1, pp. 5-22, 2020, doi: 10.1177/0047239520934018.

[2] M. J. Kintu, C. Zhu, and E. Kagambe, "Blended learning effectiveness: the relationship between student characteristics, design features and outcomes," Int. J. Educ. Technol. High. Educ., vol. 14, no. 1, 2017, doi: 10.1186/s41239-017-0043-4.

[3] J. Šabić and B. Jokić, "Elementary school pupils' aspirations for higher education: the role of status attainment, blocked opportunities and school context," Educ. Stud., vol. 47, no. 2, pp. 200-216, 2021.

[4] G. Kroll, J. Neuhaus, and W. Gordon, "Slouching toward student-centered assessment," J. Am. Hist., vol. 102, no. 4, pp. 1108-1122, 2016, doi: 10.1093/jahist/jav802.

[5] M. K. Khalil and I. A. Elkhider, "Applying learning theories and instructional design models for effective instruction," Adv. Physiol. Educ., vol. 40, no. 2, pp. 147-156, 2016, doi: 10.1152/advan.00138.2015.

[6] S. Kataoka, A. K. Langley, M. Wong, S. Baweja, and B. D. Stein, "Responding to Students with Posttraumatic Stress Disorder in Schools," Child Adolesc. Psychiatr. Clin. N. Am., vol. 21, no. 1, pp. 119-133, 2012, doi: 10.1016/j.chc.2011.08.009.

[7] N. Nako and N. Muthukrishna, "Teacher-instigated in-school interpersonal violence: Types and prevalence in South African public schools," J. Psychol. Africa, vol. 28, no. 5, pp. 371-374, 2018.

[8] S. Wang and D. Zhang, "The impact of perceived social support on students' pathological internet use: The mediating effect of perceived personal discrimination and moderating effect of emotional intelligence," Comput. Human Behav., vol. 106, May 2020, doi: 10.1016/j.chb.2020.106247.

[9] M. J. Van Ryzin and C. J. Roseth, "Cooperative learning effects on peer relations and alcohol use in middle school," J. Appl. Dev. Psychol., vol. 64, 2019, doi: 10.1016/j.appdev.2019.101059.

[10] S. Thiagarajan, et al., Instructional Development for Training Teachers of Exceptional Children: A Sourcebook. Council for Exceptional Children, Association Drive, Reston, Virginia, 1974.

[11] J. H. Lee and O. A. Shvetsova, "The impact of VR application on student's competency development: A comparative study of regular and VR engineering classes with similar competency scope," Sustain., vol. 11, no. 8, 2019, doi: 10.3390/su11082221.

[12] S. Kagan, "The Structural Approach to Cooperative Learning.," Educ. Leadersh., vol. 47, no. 4, pp. 12-15, 1990.

[13] L. Lundgren, "Cooperative learning in the science classroom," Glencoe Science Professional Series, 1994.

[14] K. Berthold, M. Nückles, and A. Renkl, "Do learning protocols support learning strategies and outcomes? The role of cognitive and metacognitive prompts," Learn. Instr., vol. 17, no. 5, pp. 564-577, 2007, doi: 10.1016/j.learninstruc.2007.09.007.

[15] T. Sato, E. Tsuda, D. Ellison, and S. R. Hodge, "Japanese elementary teachers' professional development experiences in physical education lesson studies," Phys. Educ. Sport Pedagog., vol. 25, no. 2, pp. 137-153, 2020, doi: 10.1080/17408989.2019.1692808.

[16] E. Tsuda, T. Sato, J. D. Wyant, and E. Hasegawa, "Japanese elementary teachers' experiences of physical education professional development in depopulated rural school districts," Curric. Stud. Heal. Phys. Educ., vol. 10, no. 3, pp. 262-276, 2019, doi: 10.1080/25742981.2019.1635508.

[17] N. Hollett, J. B. Sluder, S. Taunton, and C. Howard-Shaughnessy, "Teaching Body and Spatial Awareness in Elementary Physical Education Using Integration of Core Content Subjects," J. Phys. Educ. Recreat. Danc., vol. 87, no. 7, pp. 31-35, 2016, doi: 10.1080/07303084.2016.1202800.

[18] E. Tsuda, P. Ward, and J. D. Goodway, "Defining tennis content in upper elementary physical education," J. Phys. Educ. Recreat. Danc., vol. 89, no. 6, pp. 33-41, 2018, doi: 10.1080/07303084.2018.1476939.

[19] A. J. Maher, "Special educational needs in mainstream secondary school physical education: learning support assistants have their say," Sport. Educ. Soc., vol. 21, no. 2, pp. 262-278, 2016.

[20] K. A. Jenkinson, G. Naughton, and A. C. Benson, "Peer-assisted learning in school physical education, sport and physical activity programmes: A systematic review," Phys. Educ. Sport Pedagog., vol. 19, no. 3, pp. 253-277, 2014, doi: 10.1080/17408989.2012.754004

[21] I. Lyngstad, Ø. Bjerke, and P. Lagestad, "Students' views on the purpose of physical education in upper secondary school. Physical education as a break in everyday school life-learning or just fun?" Sport. Educ. Soc., vol. 25, no. 2, pp. 230-241, 2020, doi: 10.1080/13573322.2019.1573421.

[22] A. Laxdal and R. Giske, "Gender and the perceived learning environment in upper secondary school physical education," Sport. Educ. Soc., vol. 25, no. 7, pp. 779-787, 2020, doi: 10.1080/13573322.2019.1666360.

[23] E. H. Kwon and M. E. Block, "Implementing the adapted physical education E-learning program into physical education teacher education program," Research in Developmental Disabilities, vol. 69, pp. 18-29, 2017, doi: 10.1016/j.ridd.2017.07.001.

[24] K. Khadjooi, K. Rostami, and S. Ishaq, "How to use Gagne's model of instructional design in teaching psychomotor skills," Gastroenterol Hepatol Bed Bench., vol. 4, no. 3, pp. 116-119, 2011.

[25] J. Reeve and H. Jang, "What teachers say and do to support students' autonomy during a learning activity," $J$. Educ. Psychol., vol. 98, no. 1, pp. 209-218, 2006, doi: 10.1037/0022-0663.98.1.209.

[26] K. Ioannou and K. Iordanou, "Elementary school students' epistemic perspective and learning strategies in history," Learn. Res. Pract., vol. 6, no. 2, pp. 150-166, 2020, doi: 10.1080/23735082.2019.1591492.

[27] G. Shilo and N. Ragonis, "A new approach to high-order cognitive skills in linguistics: problem-solving inference in similarity to computer science," J. Furth. High. Educ., vol. 43, no. 3, pp. 333-346, 2019, doi: 10.1080/0309877X.2017.1361515. 
[28] J. H. Corpus and S. V. Wormington, "Profiles of intrinsic and extrinsic motivations in elementary school: A longitudinal analysis," J. Exp. Educ., vol. 82, no. 4, pp. 480-501, 2014, doi: 10.1080/00220973.2013.876225.

[29] I. Nebelung, "Humanistic Music Therapy in the Child Welfare Humanistic music therapy in the child welfare: Reflections on the label 'humanistic music therapy' and its correlation with the visions of the leaders of a new child welfare institution for adolescents," Voices A World Forum Music Ther., vol. 8, no. 4, pp. 1-19, 2018, doi: 10.15845/voices.v18i4.2590.

[30] R. Sanz, J. A. Peris, and J. Escámez, "Higher education in the fight against poverty from the capabilities approach: The case of Spain,” J. Innov. Knowl., vol. 2, no. 2, pp. 53-66, 2017, doi: 10.1016/j.jik.2017.03.002.

[31] E. M. DeRobertis and A. M. Bland, "Tapping the humanistic potential of self-determination theory: Awakening to paradox," Humanist. Psychol., vol. 46, no. 2, pp. 105-128, 2018, doi: 10.1037/hum0000087.

[32] V. Arghode, E. W. Brieger, and G. N. McLean, "Adult learning theories: implications for online instruction," Eur. J. Train. Dev., vol. 41, no. 7, pp. 593-609, 2017, doi: 10.1108/EJTD-02-2017-0014.

[33] G. Hornby, "Theory and practice a humanistic developmental model of counselling: A psycho-educational approach,” Couns. Psychol. Q., vol. 3, no. 2, pp. 191-203, 1990, doi: 10.1080/09515079008254247.

[34] P. Gu, Y. Zhang, and H. Gu, "Creating a technology-enhanced constructivist learning environment for research ability development in a BA Thesis Writing course,” Comput. Assist. Lang. Learn., vol. 33, no. 5-6, pp. 538-566, 2020, doi: 10.1080/09588221.2019.1576735.

[35] B. Hof, "The turtle and the mouse: how constructivist learning theory shaped artificial intelligence and educational technology in the 1960s," Hist. Educ., vol. 50, no. 1, pp. 93-111, 2021, doi: 10.1080/0046760X.2020.1826053.

[36] Y. Liu, H. Liu, Y. Xu, and H. Lu, "Online English Reading Instruction in the ESL Classroom Based on Constructivism," J. Educ. Technol. Syst., vol. 48, no. 4, pp. 539-552, 2020, doi: 10.1177/0047239519899341.

[37] G. Biesta, "Pragmatising the curriculum: Bringing knowledge back into the curriculum conversation, but via pragmatism," Curric. J., vol. 25, no. 1, pp. 29-49, 2014, doi: 10.1080/09585176.2013.874954.

[38] A. Sutinen, "Constructivism and education: Education as an interpretative transformational process," Stud. Philos. Educ., vol. 27, no. 1, pp. 1-14, 2008, doi: 10.1007/s11217-007-9043-5.

[39] C. Korgan, K. Eagan, and A. Nosal, "Educating tomorrow's reformists: factors affecting the development of undergraduates' social progressivism," Journal for the Study of Race, Nation and Culture, vol. 24, no. 6, pp. 795-816, 2018, doi: 10.1080/13504630.2017.1376282.

[40] F. A. J. Korthagen and F. G. Evelein, "Relations between student teachers' basic needs fulfillment and their teaching behavior," Teach. Teach. Educ., vol. 60, pp. 234-244, 2016, doi: 10.1016/j.tate.2016.08.021.

[41] E. Kupers, A. L. Wermser, G. McPherson, and P. ven Geert, "Children's Creativity: A Theoretical Framework and Systematic Review," Review of Educational Research, vol. 89, no. 1, pp. 93-124, 2019.

[42] E. Stern, "Individual differences in the learning potential of human beings," npj Sci. Learn., vol. 2, no. 1, 2017, doi: 10.1038/s41539-016-0003-0.

[43] D. Guthrie, "Integral Engagement: Christian Constructivism and the Social Sciences," Christ. Educ. J., vol. 16, no. 3, pp. 445-457, 2019, doi: 10.1177/0739891319875155.

[44] R. Ben-Ari and P. Kedem-Friedrich, "Restructuring heterogeneous classes for cognitive development: Social interactive perspective," Instr. Sci., vol. 28, no. 2, pp. 153-167, 2000, doi: 10.1023/A:1003806300757.

[45] J. Zambrano, F. Kirschner, J. Sweller, and P. A. Kirschner, "Effects of group experience and information distribution on collaborative learning," Instr. Sci., vol. 47, no. 5, pp. 531-550, 2019, doi: 10.1007/s11251-01909495-0.

[46] A. Raes, T. Schellens, and B. De Wever, "Web-based Collaborative Inquiry to Bridge Gaps in Secondary Science Education," J. Learn. Sci., vol. 23, no. 3, pp. 316-347, 2014, doi: 10.1080/10508406.2013.836656.

[47] H. Mulder, H. van Ravenswaaij, J. Verhagen, M. Moerbeek, and P. P. M. Leseman, "The process of early selfcontrol: an observational study in two- and three-year-olds," Metacognition Learn., vol. 14, no. 3, pp. 239-264, 2019, doi: 10.1007/s11409-019-09199-3.

[48] P. Caldarella, R. A. A. Larsen, L. Williams, K. R. Downs, H. P. Wills, and J. H. Wehby, "Effects of teachers' praise-to-reprimand ratios on elementary students' on-task behaviour," Educ. Psychol., vol. 40, no. 10, pp. 1306-1322, 2020, doi: 10.1080/01443410.2020.1711872.

[49] J. Dobbs, D. H. Arnold, and G. L. Doctoroff, "Attention in the preschool classroom: The relationships among child gender, child misbehavior, and types of teacher attention," Early Child Dev. Care, vol. 174, no. 3, pp. 281-295, 2004, doi: 10.1080/0300443032000153598.

[50] M. J. Fencl, "Fun and Creative Unit Assessment Ideas for All Students in Physical Education," J. Phys. Educ. Recreat. Danc., vol. 85, no. 1, pp. 16-21, 2014, doi: 10.1080/07303084.2014.855589.

[51] M. Leasa, M. Talakua, and J. R. Batlolona, "The development of a thematic module based on Numbered Heads Together (NHT) cooperative learning model for elementary students in Ambon, Moluccas-Indonesia," New Educ. Rev., vol. 46, no. 4, pp. 174-185, 2016, doi: 10.15804/tner.2016.46.4.15.

[52] L. Maheady, J. Michielli-Pendl, G. F. Harper, and B. Mallette, "The effects of Numbered Heads Together with and without an incentive package on the science test performance of a diverse group of sixth graders," J. Behav. Educ., vol. 15 , no. 1, pp. 25-39, 2006, doi: 10.1007/s10864-005-9002-6.

[53] J. Herranen and M. Aksela, "Student-question-based inquiry in science education," Stud. Sci. Educ., vol. 55, no. 1, pp. 1-36, 2019, doi: 10.1080/03057267.2019.1658059. 